\title{
Junctional Premature Complex by ECG
} Finding

National Cancer Institute

\section{Source}

National Cancer Institute. Junctional Premature Complex by ECG Finding. NCI Thesaurus.

Code C102652.

An electrocardiographic finding of an ectopic impulse originating in the AV junction presenting as a QRS complex of supraventricular orig in which is not preceded by a P wave. (CDISC) 